\title{
A landscape of the heritability of Fourier-transform infrared spectral wavelengths of milk samples by parity and lactation stage in Holstein cows
}

\author{
G. Rovere, ${ }^{1,2,3 *}$ G. de los Campos, ${ }^{2,3,4 *}$ R. J. Tempelman, ${ }^{1}$ A. I. Vazquez, ${ }^{2,3}$ F. Miglior, ${ }^{5,6}$ F. Schenkel, ${ }^{5}$ \\ A. Cecchinato, ${ }^{7}$ G. Bittante, ${ }^{7}$ H. Toledo-Alvarado, ${ }^{7}$ and A. Fleming ${ }^{5,6}$ \\ ${ }^{1}$ Department of Animal Science, \\ ${ }^{2}$ Department of Epidemiology and Biostatistics, \\ ${ }^{3}$ Institute for Quantitative Health Science and Engineering, and \\ ${ }^{4}$ Department of Statistics and Probability, Michigan State University, East Lansing 48824 \\ ${ }^{5}$ Centre for Genetic Improvement of Livestock, Department of Animal Biosciences, University of Guelph, Guelph, Ontario, Canada, N1G 2W1 \\ ${ }^{6}$ Canadian Dairy Network, Guelph, Ontario, Canada N1K 1E5 \\ ${ }^{7}$ Department of Agronomy, Food, Natural Resources, Animals and Environment (DAFNAE), University of Padova, 35020 Legnaro, Italy
}

\section{ABSTRACT}

Fourier-transform near- and mid-infrared (FTIR) milk spectral data are routinely collected in many countries worldwide. Establishing an optimal strategy to use spectral data in genetic evaluations requires knowledge of the heritabilities of individual FTIR wavelength absorbances. Previous FTIR heritability estimates have been based on relatively small sample sizes and have not considered the possibility that heritability may vary across parities and stages of the lactation. We used data from $\sim 370,000$ test-day records of Canadian Holstein cows to produce a landscape of the heritability of FTIR spectra, 1,060 wavelengths in the near- and mid-infrared spectrum $\left(5,011-925 \mathrm{~cm}^{-1}\right)$, by parity and month of the lactation (mo 1 to 3 and mo 1 to 6 , respectively). The 2 regions of the spectrum associated with absorption of electromagnetic energy by water molecules were estimated to have very high phenotypic variances, very low heritabilities, and very low proportion of variance explained by herd-year-season (HYS) subclasses. The near- or short-wavelength infrared (SWIR: 5,066-3,672 $\mathrm{cm}^{-1}$ ) region was also characterized by low heritability estimates, whereas the estimated proportion of the variance explained by HYS was high. The midwavelength infrared region (MWIR: $3,000-2,500 \mathrm{~cm}^{-1}$ ) and the transition between mid and long-wavelength infrared region (MWIR-LWIR: 1,500-925 $\mathrm{cm}^{-1}$ ) harbor several waves characterized by moderately high $(\geq 0.4)$ heritabilities. Most of the high-heritability regions contained wavelengths that are reported to be associated with important milk metabolites and components.

\footnotetext{
Received May 23, 2018.

Accepted September 28, 2018.

*Corresponding authors: roverega@msu.edu and gdeloscampos@epi msu.edu
}

Interestingly, these 2 same regions tended to show more variability in heritabilities between parity and lactation stage. Second parity showed heritability patterns that were distinctly different from those of the first and third parities, whereas the first 2 mo of the lactation had clearly distinct heritability patterns compared with mo 3 to 6 .

Key words: Fourier-transform infrared (FTIR), spectrometry, high-throughput phenotyping, Bayesian, BGLR software

\section{INTRODUCTION}

Fourier-transform infrared spectroscopy (FTIR) can be used to describe the molecular structure of many different materials. In the dairy industry, FTIR data derived from milk samples are routinely used to assess milk composition for payment, quality control, and herd management purposes, as well as for selective breeding. Furthermore, FTIR-derived predictions of protein (Prot\%) and fat (Fat\%) percentage from individual samples of milking cows are routinely stored in national recording systems and used as traits in genetic evaluations (ICAR, 2012).

Most research and industry applications using milk FTIR data focus on developing prediction equations for economically important phenotypes such as fine milk composition (Rutten et al., 2010, 2011; Fleming et al., 2017a,b, 2018) and technological properties of milk (Cecchinato et al., 2009, 2015). In addition, FTIR data have been shown to be a potentially valuable tool for predicting health and reproductive phenotypes (Heuer et al., 2001; Belay et al., 2017; Toledo-Alvarado et al., 2018) and for predicting residual feed intake, DMI, and methane emissions (Shetty et al., 2017a,b; Bittante and Cipolat-Gotet, 2018; Dórea et al., 2018).

Developing an optimal strategy for the use of milk FTIR data in genetic evaluations requires knowledge 
Table 1. Number of records by parity and class of DIM

\begin{tabular}{|c|c|c|c|c|c|c|}
\hline \multirow[b]{2}{*}{ Parity } & \multicolumn{6}{|c|}{ Class of DIM } \\
\hline & $5-30$ & $31-60$ & $61-90$ & $91-120$ & $121-150$ & $151-180$ \\
\hline 1 & 29,621 & 37,632 & 35,886 & 35,412 & 35,539 & 34,839 \\
\hline 2 & 15,856 & 20,903 & 20,138 & 19,522 & 19,266 & 18,668 \\
\hline 3 & 6,725 & 8,780 & 8,005 & 7,753 & 7,651 & 7,313 \\
\hline
\end{tabular}

of the heritability of absorbance at individual wavelengths. A few authors have estimated genetic parameters of individual milk FTIR wavelength absorbance data (e.g., Soyeurt et al., 2010; Bittante and Cecchinato, 2013; Wang et al., 2016; Wang and Bovenhuis, 2018). These studies have shown that absorbance (and transmittance) at certain regions of the spectrum can be moderately heritable.

However, the studies published thus far have been based on limited sample sizes $(<2,000$ cows $)$; furthermore, it might be important to know whether the heritabilities of milk FTIR data vary across parities and over the course of a lactation. Therefore, the main goal of this study was to produce a landscape of heritabilities of milk FTIR spectral data as a function of wavenumber, parity, and stage of lactation. To this end, we analyzed a Canadian data set comprising $\sim 370,000$ records of FTIR data from Holstein milking cows. To our knowledge, this represents the largest study ever conducted to estimate the wave-specific heritability of milk FTIR spectral data in dairy cattle.

\section{MATERIALS AND METHODS}

\section{Data}

Data were provided by the Canadian Dairy Network (Guelph, ON, Canada) and included FTIR spectra and yield records collected in the routine Canadian DHI milk recording system from January 2013 to June 2016. After data editing, the number of records available was 369,509 , originating from 203,516 cows and 19,164 herds.

Milk spectral data, consisting of FTIR absorbance at 1,060 data points in the infrared wavenumber range from 5,011 to $925 \mathrm{~cm}^{-1}$ (wavelength 2.00 to $10.76 \mu \mathrm{m}$ ), were available for individual test-day samples and were obtained from 2 laboratories, CanWest DHI (Guelph, ON, Canada) and Valacta (Sainte-Anne-de-Bellevue, QC, Canada). Both laboratories processed samples using MilkoScan FT6000 spectrometers (Foss, Hillerød, Denmark) with identical specifications and following the same sample processing procedures. To provide more numerical stability, each wavenumber was stan- dardized to a mean of 0 and sample variance of 1 , which additionally, facilitate the interpretability of variance components and comparability across wavenumbers. In addition to FTIR spectral data, milk yield (MY) and spectra-derived predictions of Prot $\%$ and Fat $\%$ were available for each test-day milk sample.

\section{Stratification}

We divided the data into 3 parities (first, second, and third; no data from later parities was available) and 6 stages of lactation (month 1 through 6); thus, there were 18 strata. The number of records (cows) per stratum ranged from 6,725 to 37,632 (Table 1). All analyses were conducted for each wavelength within each of these 18 strata separately. An alternative to the stratified analyses used in this study would have been to fit a multivariate model by either treating FTIR data from different parities and month of lactation as different traits or using random regression models (Meyer, 1998). However, due to computational considerations and because there were only 1.8 records per cow, we carried out a stratified analysis.

Herd-year-season (HYS) groups were formed based on 4 seasons defined as January-March, April-June, July-September, and October-December. Only records from Holstein cows and from HYS with at least 4 cows within stratum were considered.

Pedigree records were from the Canadian Dairy Network (Guelph, ON, Canada), and contained 1,477,237 animals. From here, pedigree files (one per stratum) were constructed by tracing back, for each cow with records, 3 generations of ancestors; therefore, the base population consisted of great-grandparents of the animals with records.

\section{Models}

We estimated the heritability of single-wave absorbance spectral data and single test-day MY, Prot\%, and Fat\% using a (Bayesian) animal model of the form

$$
y_{i j}=\mu+h y s_{i}+a_{j}+\varepsilon_{i j},
$$


where $y_{i j}(i=1, \ldots, n)$ represents the phenotype (e.g., absorbance data on one of the wavelengths) derived from animal $j$ within HYS $i$; $\mu$ represents the overall mean; $h y s_{i}$ is the random effect of the $i$ th HYS; $a_{j}$ is the additive genetic effect of the $j$ th cow; and $\varepsilon_{i j}$ is an error term. The vector of herd-year-season (hys = $\left.\left\{h y s_{i}\right\}\right)$ and additive effects $\left(\mathbf{a}=\left\{a_{j}\right\}\right)$ and the vector of error terms $\left(\varepsilon=\left\{\varepsilon_{i j}\right\}\right)$ were assumed to follow pairwise independent multivariate normal $(M V N)$ distributions of the form

$$
\begin{gathered}
\text { hys } \sim \operatorname{MVN}\left(0, \mathbf{I} \sigma_{\text {hys }}^{2}\right), \\
\mathbf{a} \sim M V N\left(0, \mathbf{A} \sigma_{a}^{2}\right), \\
\text { and } \varepsilon \sim M V N\left(0, \mathbf{I} \sigma_{\varepsilon}^{2}\right),
\end{gathered}
$$

respectively. Here, $\mathbf{I}$ is an identity matrix, $\mathbf{A}$ is the pedigree relationship matrix, $\sigma_{\text {hys }}^{2}$ is the variance of the herd-year-season effects, $\sigma_{a}^{2}$ is the additive genetic variance, and $\sigma_{\varepsilon}^{2}$ is the error variance. To obtain results comparable with those who have previously studied the heritability of FTIR milk spectral data (e.g., Soyeurt et al., 2010; Bittante and Cecchinato, 2013; Wang et al., 2016; Wang and Bovenhuis, 2018), we defined heritability as the inter-herd proportion of variance explained by additive genetic effects; that is,

$$
h^{2}=\frac{\sigma_{a}^{2}}{\sigma_{a}^{2}+\sigma_{\text {hys }}^{2}+\sigma_{\varepsilon}^{2}} .
$$

We also estimated the proportion of variance explained by HYS effects using

$$
\frac{\sigma_{\text {hys }}^{2}}{\sigma_{a}^{2}+\sigma_{\text {hys }}^{2}+\sigma_{\varepsilon}^{2}} .
$$

The model of expressions [1] and [2] was implemented in a fully Bayesian framework. The intercept was assigned a flat prior and the variances $\left(\sigma^{2}\right)$ were assigned independent identical scaled-inverse chi-squared priors, $\sigma^{2} \sim \chi^{-2}(d f, S)$, with $5 \mathrm{df}$ and a scale parameter (S) of 1 ; this gives relatively weak priors, with a prior expected value of $1 / 3$.

Variance components and heritabilities were estimated for each trait (either absorbance at one of the 1,060 wavelengths, or MY, Fat\%, or Prot\%) for each stratum separately, resulting in a total of 19,134 different analyses.

\section{Software}

All analyses were carried out in the $\mathrm{R}$ environment ( $\mathrm{R}$ Core Team, 2016) using Michigan State University's High-Performance Computing Cluster (https:// icer.msu.edu/). The pedigree was processed using the pedigreeR R-package (Vazquez et al., 2010). Models were fitted using the BGLR software (Pérez and de los Campos, 2014).

\section{Number of Samples and Assessment of Convergence}

We first ran a single chain (10,000 samples) every 10 wavenumbers in each of the strata. Based on inspection of the trace plots of these analyses, we decided to use a burn-in period of 2,000. Subsequently, we ran 5 chains for each wavenumber-by-stratum combination; each chain generated 12,000 samples, the first 2,000 of which were discarded as burn-in and the remaining 10,000 were thinned at a thinning interval of 5 . Subsequently, we used the Coda package (Plummer et al., 2006) to estimate, based on the 5 chains, the posterior mean, posterior standard deviation, 95\% credibility region, the effective sample size, and the Monte Carlo error.

\section{Inferences}

For each wavelength and stratum, we report the estimated posterior mean and $95 \%$ highest posterior density (HPD) regions of heritability and of the proportion of variance explained by HYS. The heritabilities of different strata were formally compared using contrasts. For each of the contrasts tested (see below), we estimated the posterior probability that the contrasts (e.g., parity 1 vs. parity 2 , or first stratum vs. fifth stratum) yielded a 5-percentage-point difference in heritability. We used this threshold to declare a difference in heritability that is genetically relevant. To illustrate the procedure, suppose that

$$
\mathbf{h}_{j[s]}^{2}=\left(h_{j(1)[s]}^{2}, \ldots, h_{j(18)[s]}^{2}\right)^{\prime}
$$

represents a vector containing a sample $(s)$ from the posterior distribution of the heritability of the $j$ th wavelength $(j=1, \ldots, 1,060)$ of each strata, and let $\mathbf{k}_{18 \times 1}$ be a contrast satisfying $\mathbf{1}^{\prime} \mathbf{k}=0$. A sample from the posterior distribution of this contrast $\left(c_{[s]}\right)$ was obtained using $c_{[s]}=\mathbf{k}^{\prime} \mathbf{h}_{j[s]}^{2}$. For instance, if we wished to compare the first and third strata, then $c_{[s]}=(1,0,-1,0, \ldots, 0)^{\prime} \mathbf{h}_{j[s]}^{2}=h_{j(1)[s]}^{2}-h_{j(3)[s]}^{2}$. These samples 
were then used to estimate the posterior probability that $c_{[s]}$ was either smaller or greater than 0.05 . This was done using a one-sided probability measure $\max \left\{p\left(c_{[s]}\langle-0.05|\right.\right.$ data $), p\left(c_{[s]}>0.05 \mid\right.$ data $\left.)\right\}$. We used this approach to test differences between parities, months, and individual strata.

\section{RESULTS}

Milk yield increased from first to third parity. Likewise, MY increased from the first to the second month of lactation and decreased thereafter (especially for second- and third-parity cows). Means for Prot\% and Fat\% were similar between parities, with the former decreasing from mo 1 to mo 2 and the latter also to mo 3 , and then both increasing almost linearly thereafter. Supplemental Figure S1 (https://doi.org/10.3168/jds .2018-15109) shows the phenotypic means ( \pm 1 phenotypic standard deviation) of MY, Prot\%, and Fat\%.

The average absorbance was remarkably similar across strata (Figure S2; https://doi.org/10.3168/jds .2018-15109). We followed the division of the spectrum in 5 regions used by (Bittante and Cecchinato, 2013). The short-wavelength infrared (SWIR) region spanned wavenumbers 5,011 and $3,673 \mathrm{~cm}^{-1}$; the transition region between SWIR and mid-wavelength infrared region (SWIR-MWIR) was considered between wavenumber 3,669 and $3,052 \mathrm{~cm}^{-1}$. The MWIR was divided in 2 regions: MWIR1, between wavenumbers 3,048 and $1,701 \mathrm{~cm}^{-1}$, and MWIR2, between wavenumbers 1,698 and $1,586 \mathrm{~cm}^{-1}$. The last region defined was the transition between MWIR and long-infrared region between wavenumbers 1,582 and $925 \mathrm{~cm}^{-1}$ (MWIR-LWIR). The regions of the spectrum exhibiting more (withinstrata) phenotypic variation were those associated with absorbance by water molecules.

The estimated heritabilities for MY, Prot\%, and Fat\% increased from mo 1 to mo 2 of the lactation (especially for protein), but showed no clear patterns in later stages of the lactation (Figure S3; https://doi .org/10.3168/jds.2018-15109). Among the yield traits, Prot $\%$ had the highest estimated heritabilities followed by Fat\% and MY, but there were no clear differences in heritability estimates across lactations.

Figure 1 shows the average (across strata) proportion of the total variance explained by each of the random effects included in the model (genetic, HYS, and the error term). The SWIR region of the spectra showed a stable pattern of low heritability estimates $(\sim 0.10)$ and a sizable proportion $(\sim 0.42)$ of variance explained by HYS. The SWIR-MWIR and MWIR2 regions, which are both associated with absorbance by water molecules, were also regions of very low heritability $(<0.10)$. Fur- thermore, in these regions, the proportion of variance explained by HYS was also very small $(\sim 0.10)$. Thus, SWIR-MWIR and MWIR2 were regions where most of the phenotypic variance was unexplained residual variability. Finally, the MWIR1 and MWIR-LWIR regions contained some of the highest heritability estimates and a relatively high and constant proportion of variance explained by the HYS component (Supplemental Figure S4; https://doi.org/10.3168/jds.2018-15109).

Wavenumber-specific heritability estimates for each of the 18 (parity $\times$ stage of lactation) strata are displayed in Supplemental Figure S5 (https://doi.org/10 $.3168 /$ jds.2018-15109). The actual estimates of variance components and of the heritabilities, together with credibility regions and Monte Carlo errors for band and strata, are provided in Supplemental File S1 (https://doi.org/10.3168/jds.2018-15109). Figure 2 (and Supplemental Figures S6 and S7; https://doi.org/ 10.3168/jds.2018-15109) display the estimated (onesided) probabilities that the heritabilities differ by 5 percentage points, using contrasts between parities and between months of lactations (Figure 2), and pairwise contrasts between months of lactation within and between parities (Supplemental Figures S6 and S7). The heritability of wavenumbers in the SWIR-MWIR and MWIR2 regions were consistently low across strata. The posterior probability analyses (see Figure 2 and Supplemental Figures S6 and S7) indicates that most of the differences in heritability in those 2 regions were not greater than 5 percentage points with high confidence, except for some wavenumbers in the limits of the region MWIR2. The waves in the SWIR range had low estimated heritabilities with differences in heritability estimates between strata being not greater than 5 percentage points for most contrasts; however, a few contrasts had differences in heritability greater than 5 percentage points with high confidence (e.g., see contrasts between mo 1 and each of the other months in Figure 2). In contrast, the MWIR1 and MWIR-LWIR regions were characterized by high heritability and important differences between strata (see Figures 2 and 3 and Supplemental Figures S5 to S7; https://doi.org/ 10.3168/jds.2018-15109). Therefore, in what follows, we focus on the results obtained for these 2 important regions of the spectra.

Figure 3 shows the estimated heritabilities (and 95\% HPD credibility regions) by wavelength and by parity $\times$ month-of-lactation strata for wavelength numbers between 3,120 and $925 \mathrm{~cm}^{-1}$. In the MWIR1 and MWIRLWIR regions, we detected systematic differences between parities (with parity 2 being most different in its heritability profile) as well as between months (in general, mo 1 and 2 showed heritability patterns that were different from those of mo 3 to 6 ; see Figure 3 ). 


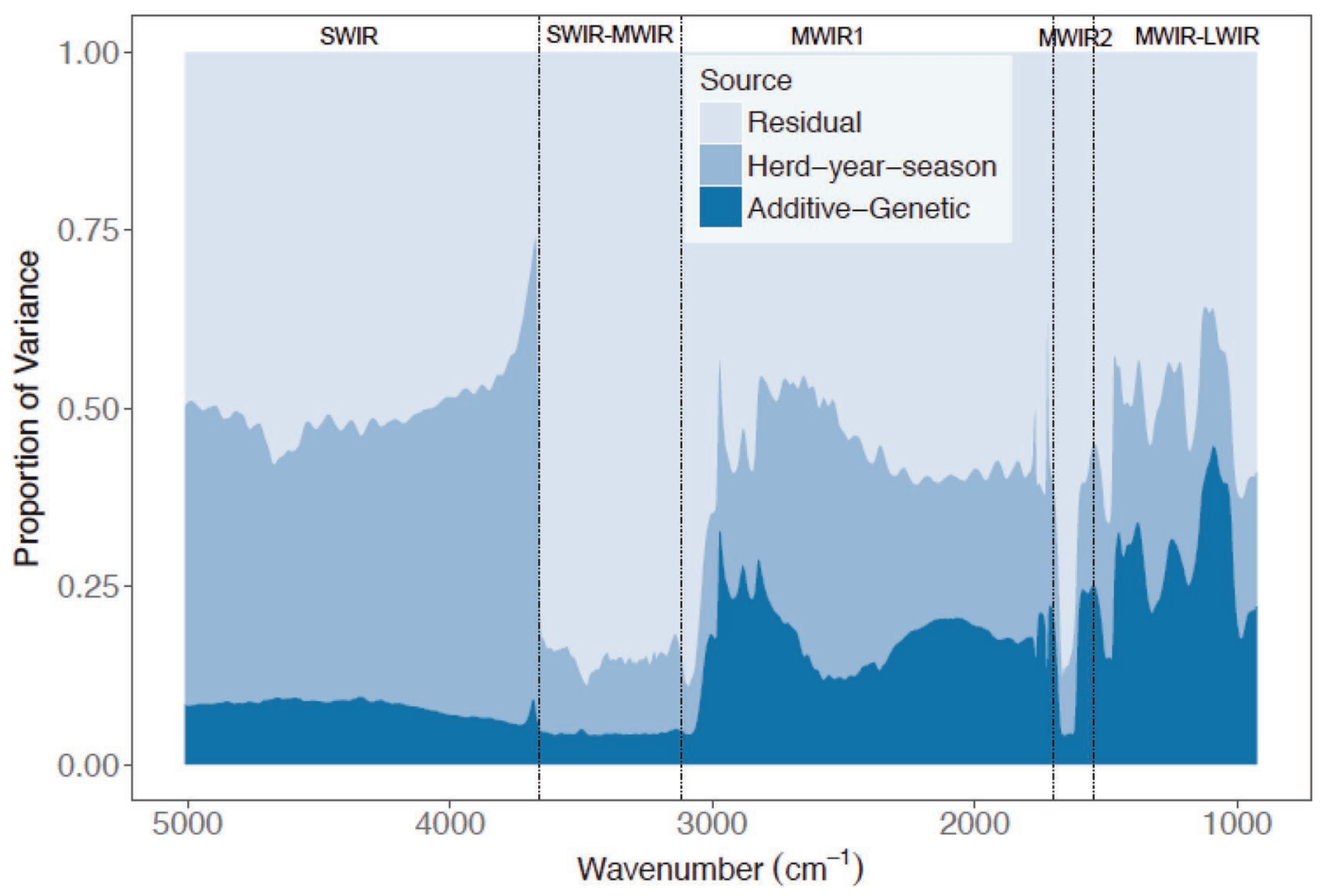

Figure 1. Proportion of phenotypic variance explained by genetic (heritability), herd-year-season effects, and the error term, averaged over the 18 data strata analyzed, by wavenumber. SWIR = short-wavelength infrared region; MWIR = mid-wavelength infrared region, separated into 2 regions (MWIR1 and MWIR2); LWIR = long-wavelength infrared region.

In the MWIR1 region, there seemed to be 2 different heritability patterns across lactation stages. In the first month of lactation, there was a peak in heritability estimates for wavenumbers close to $2,530 \mathrm{~cm}^{-1}$ $\left(2,546-2,526 \mathrm{~cm}^{-1}\right)$. This peak, which is clearly defined in the first month in parities 1 and 3 , then evolves into a well-defined valley with low heritability estimates toward the fourth through sixth months of the lactation. On the other hand, the region containing wavenumbers $>2,827 \mathrm{~cm}^{-1}$, which had low heritability estimates in the first month of the lactation, evolved into a single peak (in parity 1) and several (local) peaks toward the fourth and fifth months of the lactation. These 2 patterns were observed in parity 1 and 3 , whereas parity 2 presented lower heritability estimates and a more uniform pattern across different months of lactation, without the 2 clear patterns observed in parities 1 and 3 (Figure 3).

The MWIR-LWIR region (also referred to as the "fingerprint" region) contained some of the wavelengths with the highest heritability estimates and exhibited patterns that (with differences in level) were similar across parity and month of lactation. In this region, we observed 3 consecutive peaks of high-heritability estimates with valleys in between. These 3 peaks, which occurred around wavenumbers $1,100,1,240$, and 1,385 $\mathrm{cm}^{-1}$ are very well defined in mo 2,3 , and 4 of lactation in the 3 parities.

\section{DISCUSSION}

Milk spectral data are routinely collected in commercial dairy farms in North America, Europe, and many other countries worldwide. This information can be used for management and breeding purposes. Currently, milk spectral data are used to derive phenotypes (e.g., Fat\%, Prot\%), many of which are used for payment purposes and as "traits" in genetic evaluations. The eventual utility of the use of milk FTIR spectra for indirect selection depends on the genetic correlation between the spectra-derived traits and the selection objective(s) and on the heritability of the spectra. Therefore, knowledge about the heritability of milk FTIR data is needed for efficient use of this information in selection. Recognizing that the heritability of milk FTIR spectra may vary between parity and stage of lactation, we report single-wave estimates of heritability obtained from analyses stratified by those factors.

The results obtained for MY, Fat\%, and Prot\% were in line with those previously reported for the same population (Nixon et al., 2009; Fleming et al., 2017a,b). Although the heritability estimates for these traits did 
not show a clear pattern between parities, clearer differences were found between months within parities. Heritability estimates tended to increase from the first through the sixth month of lactation. Previous studies based on random regression models have reported high heritabilities very early in the lactation $(\mathrm{DIM} \leq 5)$ followed by an abrupt reduction in heritability in the second and third weeks of the lactation and a slow but steady increase in heritability thereafter (Jamrozik and Schaeffer, 1997; Jamrozik et al., 1997; Nixon et al., 2009).

For individual wavenumbers, our heritability estimates ranged from values near zero (in the SWIRMWIR and MWIR2 regions) to values of about 0.55 (in the MWIR-LWIR regions). Our variance component analyses enabled us to classify the regions of the infrared spectrum analyzed into 3 main groups.

Group 1 included the SWIR-MWIR and the MWIR2 regions; these regions (which are associated with absorbance by water molecules) have very high phenotypic variation (Supplemental Figure S2; https://doi.org/ 10.3168/jds.2018-15109) and very low proportion of variance explained both by genetic factors and by herd management practices and seasonal differences (Figure 1). Our heritability estimates for these 2 regions agree with results reported previously (e.g., Soyeurt et al., 2010; Bittante and Cecchinato, 2013; Wang et al., 2016). However, toward the right-hand limit of MWIR2 region, near wavenumber $1,550 \mathrm{~cm}^{-1}$, there was a clear estimated increase in heritabilities. This increase was evident within all parities and stages of lactations, but it was more marked toward the later stages (until mo 6) of lactation. Wavelengths in this region have been associated with casein (Hewavitharana and van Brakel, 1997) and proteins in general (Luinge et al., 1993; Heuer et al., 2001; Kaylegian et al., 2009). Some of the wavelengths in this region have also been associated with pregnancy status (Toledo-Alvarado et al., 2018).

Group 2 comprised wavelengths in the SWIR region. This region was characterized by low heritability estimates and high estimates of the proportion of variance explained by HYS (see Figure 1). Within strata, heritability estimates in this region were very similar across wavelengths. The similarity of heritability estimates across wavelengths in the SWIR region is likely a direct consequence of the extremely high phenotypic correlation between wavelengths (the average lag correlation between wavelengths in the SWIR region was $\geq 0.99$ for lags 1 to 25 and $\geq 0.98$ for lags 1 to 50 ; therefore, many of the wavelengths in the regions can probably be regarded as the same trait). Between strata, however, there were some systematic differences

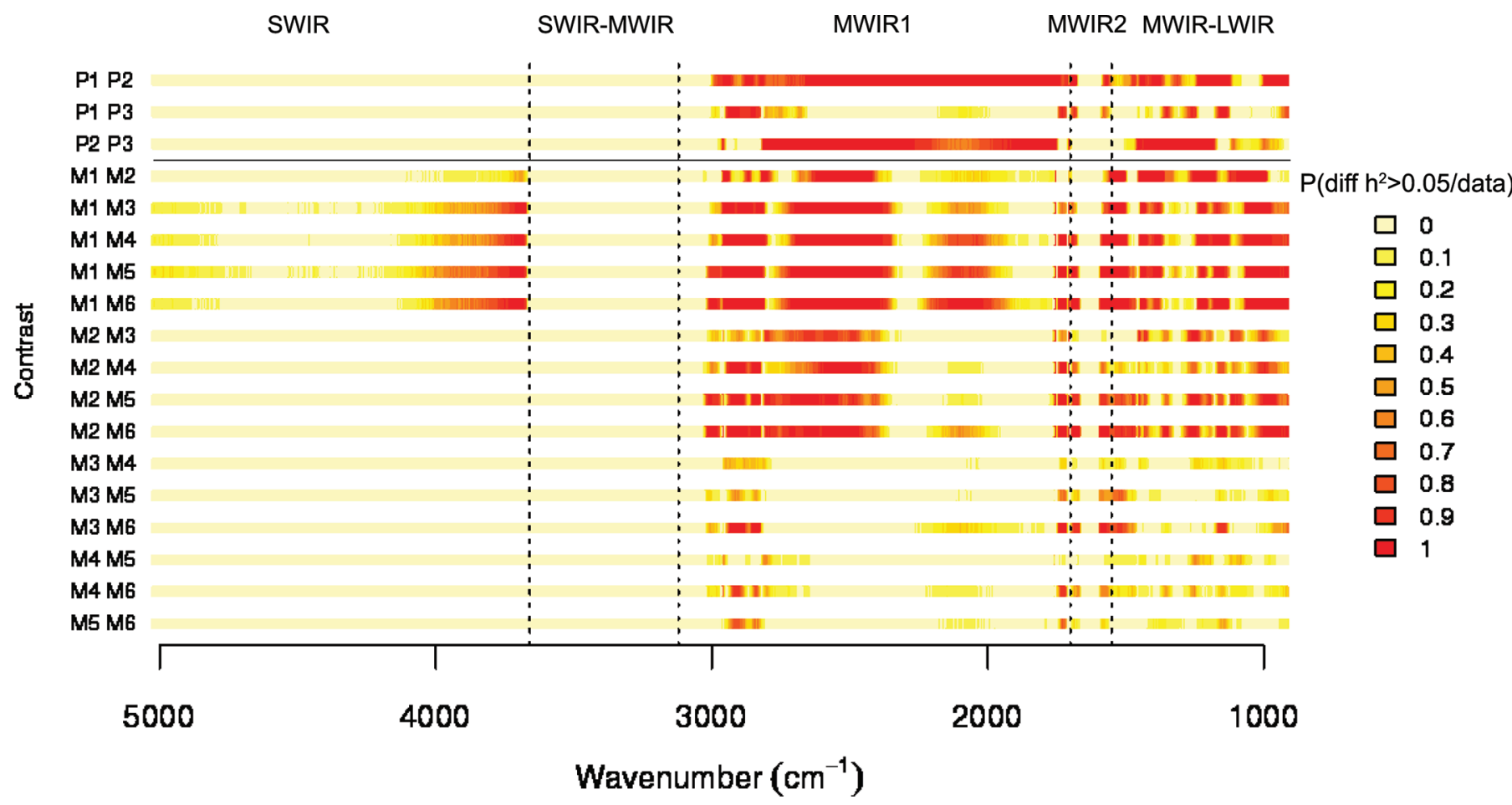

Figure 2. Posterior probability of a difference in heritability greater than 0.05 (diff $\left.\mathrm{h}^{2}>0.05\right)$ by wavelength and main effects contrast $\left(\mathrm{P}_{1}, \mathrm{P}_{2}\right.$, $\mathrm{P}_{3}=$ parity 1 , parity 2 , and parity $3 ; \mathrm{M}_{1}, \ldots, \mathrm{M}_{6}=$ month $1, \ldots$, month 6 ); SWIR = short-wavelength infrared region; MWIR = mid-wavelength infrared region, separated into 2 regions (MWIR1 and MWIR2); LWIR = long-wavelength infrared region. 


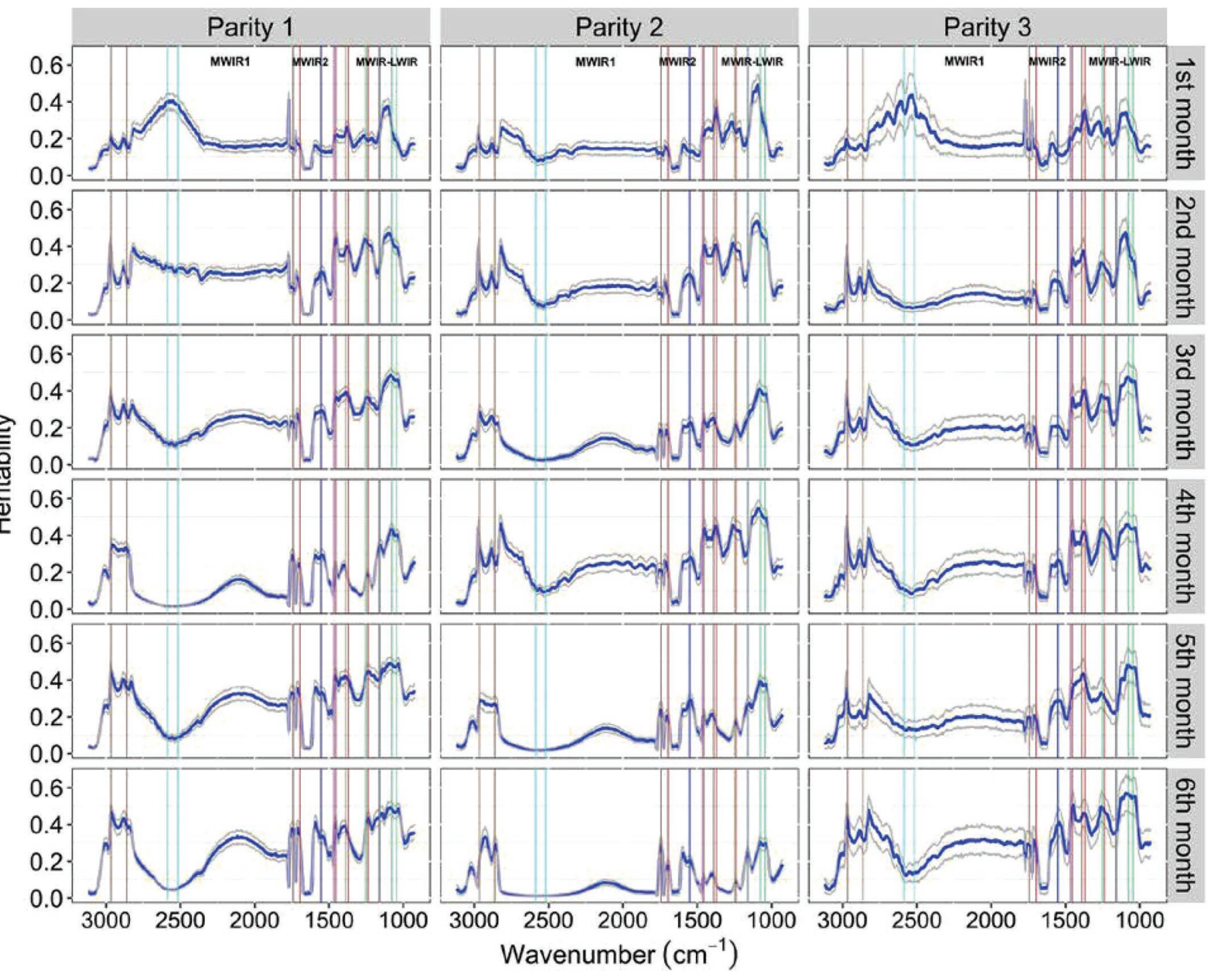

Figure 3. Estimated heritability [95\% highest posterior density (HPD) credibility region] of individual wavelengths in the regions between wavenumbers $3,120 \mathrm{~cm}^{-1}$ and $925 \mathrm{~cm}^{-1}$, by parity (1,2, and 3) and stage of lactation (months 1 to 6 ). MWIR = mid-wavelength infrared region, separated into 2 regions (MWIR1 and MWIR2); LWIR = long-wavelength infrared region. Vertical lines indicate wavenumbers reported to be associated with acetone (red, Hansen, 1998; Heuer et al., 2001), urea (magenta, Hansen, 1998), protein (blue, Luinge et al., 1993; Heuer et al., 2001; Kaylegian et al., 2009), lactose (green, Luinge et al., 1993; Heuer et al., 2001; Kaylegian et al., 2009), fat (brown, Luinge et al., 1993; Kaylegian et al., 2009), and cystine and cysteine amino acids (light blue, Hewavitharana and van Brakel, 1997).

in heritabilities, but these differences tended to be, for most of the contrasts, smaller than 5 percentage points (Supplemental Figures S6 and S7; https://doi.org/10 .3168/jds.2018-15109). Exceptions to this included the contrast between mo 1 and later months of the lactation (see Figure 2).

Our heritability estimates in the SWIR region were similar to those reported by Bittante and Cecchinato (2013) for Brown Swiss and by Soyeurt et al. (2010) for Belgian Holstein. Using data from Dutch Holsteins, Wang et al. (2016) reported much higher heritability estimates for this region. The results reported by Wang et al. (2016) for this region of the spectra are unusually high compared with those of previous studies and our own results. They noted in their data set that many wavelengths in the SWIR region were highly associated with variants in the $D G A T$ (diacylglycerol o-acyltransferase 1) gene. Some of the variants in the DGAT gene segregating in the population analyzed by Wang et al. (2016) may have more extreme allele frequencies in other populations, which might explain the different heritability estimates between studies. However, it is worth noting that in the data set analyzed by Wang et al. (2016), the average herd had $\sim 4.7$ cows; this, 
together with small sample size, may have limited the ability of the study to disentangle genetic and HYS variance.

Interestingly, toward the end of the SWIR region (near wavenumber $3,683 \mathrm{~cm}^{-1}$ ), we observed a peak in heritability estimates. This same peak has been reported by the studies referenced above. More recently, wavenumber $3,683 \mathrm{~cm}^{-1}$ was reported to be associated with pregnancy status (Toledo-Alvarado et al., 2018), and a contiguous wave $\left(3,686 \mathrm{~cm}^{-1}\right)$ has been reported to be associated with protein content (Wang and Bovenhuis, 2018).

Group 3 included the MWIR1 and MWIR-LWIR regions, which were characterized by wavelengths with high heritabilities and important differences in heritabilities between parity and month of lactation. These regions also contained wavelengths reported to be associated with important milk components (see Figure 3 and the references provided in the legend).

The average (across strata) heritability patterns found our study for the MWIR1 and MWIR-LWIR regions were similar to those previously reported in the literature; however, our heritability estimates were higher than those obtained in Brown Swiss by Bittante and Cecchinato (2013), similar to those reported by Soyeurt et al. (2010) and lower than the values obtained by Wang et al. (2016) in Belgian and Dutch Holstein, respectively.

The results displayed in Figure 3 and the contrast analyses (Figure 2 and Supplemental Figures S6 and S7; https://doi.org/10.3168/jds.2018-15109) suggest that within the MWIR1 region, the heritability patterns (across waves) for the first 2 mo of lactation were markedly different than those observed in later months of lactation. Our study also suggests that parities 1 and 3 had similar heritability patterns, which were different from those of parity 2 . The most obvious differences occurred near wavenumbers 3,000 and $2,500 \mathrm{~cm}^{-1}$. In the sector of the wavenumbers 2,862 to $3,000 \mathrm{~cm}^{-1}$, several contiguous heritability peaks appear that are well defined in third and later months of lactation. This region has been associated with fat yield (e.g., Bittante and Cecchinato, 2013) and Fat\% (e.g., Wang and Bovenhuis, 2018) and with specific fatty acids [e.g., palmitic (C16:0); Ferragina et al., 2015]. Interestingly, the same wavenumbers that were characterized by high heritability estimates in mo 3 to 4 also had very low estimated heritabilities in the first month of the lactation (Figure 3). Milk composition changes over the course of the lactation; it is particularly interesting that the peak of heritability in the region 2,862 to $3,000 \mathrm{~cm}^{-1}$ happens later in lactation, when energy balance often becomes positive and milk fat depends more on de novo mammary synthesis of fatty acids (Gross et al., 2011).
The other important difference in heritability estimates across strata within the MWIR1 region appeared close to wavenumber $2,530 \mathrm{~cm}^{-1}\left(2,546-2,526 \mathrm{~cm}^{-1}\right)$. Here, in the first month of lactation in parities 1 and 3 , there was a peak in heritability estimates $(\sim 0.40)$. This peak devolved into a "valley" with very low heritability estimates toward the fourth month of lactation. The first 2 mo of the lactation are recognized to be critical in defining production over the whole lactation, as well as health and reproductive outcomes (Berglund and Danell, 1987). Our study also indicated that these 2 important months have quite different heritability patterns in the MWIR1 region of the spectra. Some studies (e.g., Hewavitharana and van Brakel, 1997) indicate that wavelengths in this region may capture absorbance by the amino acids cystine and cysteine and $\mathrm{S}-\mathrm{H}$ stretching, which are mainly present in whey protein. In this same micro-region, some of the wavelengths are reported to be associated with fresh cheese yield and with the recovery of milk fat in cheese (Ferragina et al., 2015).

In first-parity Dutch Holstein cows, Wang et al. (2016) obtained heritability estimates between 0.30 and 0.40 for wavenumbers in the range 2,500 to $2,700 \mathrm{~cm}^{-1}$, and a significant effect of the $\kappa$-casein polymorphism around wavenumber $2,529 \mathrm{~cm}^{-1}$. More recently, within the same Dutch population, Wang and Bovenhuis (2018) reported heritability estimates of 0.39 and 0.34 for wavenumbers 2,518 and $2,587 \mathrm{~cm}^{-1}$, respectively. These heritability estimates agree with what we obtained in this region for mo 1 and 2 of lactation within the first and third parities. The same authors found these wavelengths phenotypically associated with FTIR-predicted Fat\% $\left(2,518 \mathrm{~cm}^{-1}\right)$ and lactose percentage $\left(2,587 \mathrm{~cm}^{-1}\right)$; however, the same wavelengths were not associated with FTIR-predicted Prot\%. In the study by Wang and Bovenhuis (2018), wavenumbers 2,518 and $2,587 \mathrm{~cm}^{-1}$ were associated with several SNP in a sub-region of chromosome 1 of the bovine genome where a QTL for the concentration of phosphorus in milk has been reported (SLC37A1, Buitenhuis et al., 2015; Kemper et al., 2016).

Finally, the highest heritability estimates were found in the MWIR-LWIR region, from wavenumber 1,550 to $925 \mathrm{~cm}^{-1}$. Some wavelengths had heritability estimates even higher than those of Prot\% and Fat\%. The region showed 4 contiguous and well-defined peaks in heritability estimates. Importantly, each of these peaks occurred in regions where previous studies have reported associations with important milk components, including fat $\left(1,466 \mathrm{~cm}^{-1}, 1,160 \mathrm{~cm}^{-1}\right.$, Luinge et al., 1993; Kaylegian et al., 2009), lactose $\left(1,400 \mathrm{~cm}^{-1}, 1,250\right.$ $\mathrm{cm}^{-1}, 1,157 \mathrm{~cm}^{-1}, 1,074 \mathrm{~cm}^{-1}, 1,045 \mathrm{~cm}^{-1}$, Luinge et al., 1993; Heuer et al., 2001; Kaylegian et al., 2009), 
acetone $\left(1,370 \mathrm{~cm}^{-1}, 1,238 \mathrm{~cm}^{-1}\right.$, Hansen, 1998; Heuer et al., 2001), and urea $\left(1,465 \mathrm{~cm}^{-1}, 1,161 \mathrm{~cm}^{-1}\right.$, Hansen, 1998). These 4 consecutive peaks are very well defined in parity 3 in the third and later months of the lactations but lesser so within all other strata.

Currently, milk spectral data are used to predict phenotypes, many of which are used as traits in genetic evaluations. However, the best predictor of a phenotype is not necessarily equivalent to the best predictor of the genetic merit for the same trait. Optimal prediction of genetic merit using information from indicator traits is achieved using selection indices (e.g., Hazel, 1943). The accuracy of an index is a function of the heritability of the index and the genetic correlation between the index and the aggregate genotype defined by the selection goal. This study shows that several wavenumbers in the mid-infrared spectrum are moderately to highly heritable. Thus, it should be possible to derive heritable indices from FTIR data. Moreover, the fact that the heritability peaks in the MWIR-LWIR region coincide with wavelengths reported to be associated with important milk components and with health and reproductive outcomes (de Roos et al., 2007; Soyeurt et al., 2012; Toledo-Alvarado et al., 2018) is promising, because it suggests that the same wavenumbers that are moderately to highly heritable are also phenotypically associated with important traits. However, future research should focus on studying the patterns of genetic correlations between milk spectra and economically and environmentally relevant traits (e.g., milk composition, reproductive, health, feed efficiency, or greenhouse gas emissions), as well as in the study of the genetic correlations of absorbance at individual wavenumbers between parities and stage of lactation. This information, together with heritability estimates such as those presented in this study, will pave the way toward a more efficient integration of milk spectra data in genetic evaluations.

\section{CONCLUSIONS}

Within the mid-infrared region of the spectrum for dairy cattle milk samples, the MWIR1 and MWIRLWIR regions contained wavelengths with moderately high heritability. These 2 regions are also characterized by substantial heterogeneity in the heritability of individual wavelengths across parities and stages of lactation. More importantly, most of the heritability peaks in these regions occurred at wavenumbers previously reported to be associated with important milk molecules and milk components as well as reproductive outcomes. This information should be considered when defining optimal strategies for the inclusion of FTIR data (and FTIR-derived traits) in genetic evaluations.

\section{ACKNOWLEDGMENTS}

We are grateful for the valuable comments provided by two anonymous reviewers as well as the science editor. GR, GdlC, AIV, and RJT acknowledge financial support from the USDA (Washington, DC; PAPMEAGER, 2017-67007-25947). The development and maintenance of the BGLR package was supported by the National Institutes of Health (Bethesda, MD; R01 101219). Funding for the collection of milk spectra is by Agriculture and Agri-Food Canada and by additional contributions from Dairy Farmers of Canada, the Canadian Dairy Network (Ottawa, ON, Canada), and the Canadian Dairy Commission under the Agri-Science Clusters Initiative (Dairy Farmers of Canada, Agriculture and Agri-Food Canada, the Canadian Dairy Network, and the Canadian Dairy Commission).

\section{REFERENCES}

Belay, T. K., M. Svendsen, Z. M. Kowalski, and T. Ådnøy. 2017. Genetic parameters of blood $\beta$-hydroxybutyrate predicted from milk infrared spectra and clinical ketosis, and their associations with milk production traits in Norwegian Red cows. J. Dairy Sci. 100:6298-6311. https://doi.org/10.3168/jds.2016-12458.

Berglund, B., and B. Danell. 1987. Live weight changes, feed consumption, milk yield and energy balance in dairy cattle during the first period of lactation. Acta Agric. Scand. 37:495-509. https://doi .org/10.1080/00015128709436581.

Bittante, G., and A. Cecchinato. 2013. Genetic analysis of the Fouriertransform infrared spectra of bovine milk with emphasis on individual wavelengths related to specific chemical bonds. J. Dairy Sci. 96:5991-6006. https://doi.org/10.3168/jds.2013-6583.

Bittante, G., and C. Cipolat-Gotet. 2018. Direct and indirect predictions of enteric methane daily production, yield, and intensity per unit of milk and cheese, from fatty acids and milk Fouriertransform infrared spectra. J. Dairy Sci. https://doi.org/10.3168/ jds.2017-14289.

Buitenhuis, B., N. A. Poulsen, L. B. Larsen, and J. Sehested. 2015. Estimation of genetic parameters and detection of quantitative trait loci for minerals in Danish Holstein and Danish Jersey milk. BMC Genet. 16:52. https://doi.org/10.1186/s12863-015-0209-9.

Cecchinato, A., A. Albera, C. Cipolat-Gotet, A. Ferragina, and G. Bittante. 2015. Genetic parameters of cheese yield and curd nutrient recovery or whey loss traits predicted using Fourier-transform infrared spectroscopy of samples collected during milk recording on Holstein, Brown Swiss, and Simmental dairy cows. J. Dairy Sci. 98:4914-4927. https://doi.org/10.3168/jds.2014-8599.

Cecchinato, A., M. De Marchi, L. Gallo, G. Bittante, and P. Carnier. 2009. Mid-infrared spectroscopy predictions as indicator traits in breeding programs for enhanced coagulation properties of milk. J. Dairy Sci. 92:5304-5313. https://doi.org/10.3168/jds.2009-2246.

de Roos, A. P. W., H. J. C. M. van den Bijgaart, J. Hørlyk, and G. de Jong. 2007. Screening for subclinical ketosis in dairy cattle by Fourier transform infrared spectrometry. J. Dairy Sci. 90:1761-1766. https://doi.org/10.3168/jds.2006-203.

Dórea, J. R. R., G. J. M. Rosa, K. A. Weld, and L. E. Armentano. 2018. Mining data from milk infrared spectroscopy to improve feed intake predictions in lactating dairy cows. J. Dairy Sci. 101:5878 5889. https://doi.org/10.3168/jds.2017-13997.

Ferragina, A., G. de los Campos, A. I. Vazquez, A. Cecchinato, and G. Bittante. 2015. Bayesian regression models outperform partial least squares methods for predicting milk components and technological properties using infrared spectral data. J. Dairy Sci. 98:8133-8151. https://doi.org/10.3168/jds.2014-9143. 
Fleming, A., F. S. Schenkel, F. Malchiodi, R. A. Ali, B. Mallard, M. Sargolzaei, J. Jamrozik, J. Johnston, and F. Miglior. 2018. Genetic correlations of mid-infrared-predicted milk fatty acid groups with milk production traits. J. Dairy Sci. 101:4295-4306. https://doi .org/10.3168/jds.2017-14089.

Fleming, A., F. S. Schenkel, J. Chen, F. Malchiodi, V. Bonfatti, R. A. Ali, B. Mallard, M. Corredig, and F. Miglior. 2017a. Prediction of milk fatty acid content with mid-infrared spectroscopy in Canadian dairy cattle using differently distributed model development sets. J. Dairy Sci. 100:5073-5081. https://doi.org/10.3168/ jds.2016-12102.

Fleming, A., F. S. Schenkel, A. Koeck, F. Malchiodi, R. A. Ali, M. Corredig, B. Mallard, M. Sargolzaei, and F. Miglior. 2017b. Heritabilities of measured and mid-infrared predicted milk fat globule size, milk fat and protein percentages, and their genetic correlations. J. Dairy Sci. 100:3735-3741. https://doi.org/10.3168/jds .2016-12243.

Gross, J., H. A. van Dorland, R. M. Bruckmaier, and F. J. Schwarz. 2011. Milk fatty acid profile related to energy balance in dairy cows. J. Dairy Res. 78:479-488. https://doi.org/10.1017/ S0022029911000550.

Hansen, P. W. 1998. Urea determination in milk using Fourier transform infrared spectroscopy and multivariate calibration. Milchwissenschaft 53:251-255.

Hazel, L. N. 1943. The genetic basis for constructing selection indexes. Genetics 28:476-490.

Heuer, C., H. J. Luinge, E. T. Lutz, Y. H. Schukken, J. H. van der Maas, H. Wilmink, and J. P. Noordhuizen. 2001. Determination of acetone in cow milk by Fourier transform infrared spectroscopy for the detection of subclinical ketosis. J. Dairy Sci. 84:575-582. https: //doi.org/10.3168/jds.S0022-0302(01)74510-9.

Hewavitharana, A. K., and B. van Brakel. 1997. Fourier transform infrared spectrometric method for the rapid determination of casein in raw milk. Analyst (Lond.) 122:701-704. https://doi.org/10 $.1039 / \mathrm{A} 700953 \mathrm{D}$

ICAR. 2012. Technical Series no.16. International Strategies and new developments in milk analysis. VI ICAR Reference Laboratory Network Meeting. O. Leray, ed. ICAR, Cork, Ireland.

Jamrozik, J., and L. R. Schaeffer. 1997. Estimates of genetic parameters for a test day model with random regressions for yield traits of first lactation Holsteins. J. Dairy Sci. 80:762-770. https://doi .org/10.3168/jds.S0022-0302(97)75996-4.

Jamrozik, J., L. R. Schaeffer, Z. Liu, and G. Jansen. 1997. Multiple trait random regression test day model for production traits. Interbull Bull. 16:43-47.

Kaylegian, K. E., J. M. Lynch, J. R. Fleming, and D. M. Barbano. 2009. Influence of fatty acid chain length and unsaturation on mid-infrared milk analysis1. J. Dairy Sci. 92:2485-2501. https:// doi.org/10.3168/jds.2008-1910.

Kemper, K. E., M. D. Littlejohn, T. Lopdell, B. J. Hayes, L. E. Bennett, R. P. Williams, X. Q. Xu, P. M. Visscher, M. J. Carrick, and M. E. Goddard. 2016. Leveraging genetically simple traits to identify small-effect variants for complex phenotypes. BMC Genomics 17:858. https://doi.org/10.1186/s12864-016-3175-3.

Luinge, H. J., E. Hop, E. T. G. Lutz, J. A. van Hemert, and E. A. M. de Jong. 1993. Determination of the fat, protein and lactose content of milk using Fourier transform infrared spectrometry. Anal. Chim. Acta 284:419-433. https://doi.org/10.1016/0003 $-2670(93) 85328-\mathrm{H}$.
Meyer, K. 1998. Estimating covariance functions for longitudinal data using a random regression model. Genet. Sel. Evol. 30:221. https:/ /doi.org/10.1186/1297-9686-30-3-221.

Nixon, M., J. Bohmanova, J. Jamrozik, L. R. Schaeffer, K. Hand, and F. Miglior. 2009. Genetic parameters of milking frequency and milk production traits in Canadian Holsteins milked by an automated milking system. J. Dairy Sci. 92:3422-3430. https://doi .org $/ 10.3168 /$ jds.2008-1689.

Pérez, P., and G. de los Campos. 2014. Genome-wide regression and prediction with the BGLR statistical package. Genetics 198:483495. https://doi.org/10.1534/genetics.114.164442.

Plummer, M., N. Best, K. Cowles, and K. Vines. 2006. CODA: Convergence Diagnosis and Output Analysis for MCMC. R News 6:7-11.

R Core Team. 2016. R: A Language and Environment for Statistical Computing. R Foundation for Statistical Computing, Vienna, Austria.

Rutten, M. J. M., H. Bovenhuis, J. M. L. Heck, and J. A. M. van Arendonk. 2011. Predicting bovine milk protein composition based on Fourier transform infrared spectra. J. Dairy Sci. 94:5683-5690. https://doi.org/10.3168/jds.2011-4520.

Rutten, M. J. M., H. Bovenhuis, and J. A. M. van Arendonk. 2010. The effect of the number of observations used for Fourier transform infrared model calibration for bovine milk fat composition on the estimated genetic parameters of the predicted data. J. Dairy Sci. 93:4872-4882. https://doi.org/10.3168/jds.2010-3157.

Shetty, N., G. Difford, J. Lassen, P. Løvendahl, and A. J. Buitenhuis. 2017a. Predicting methane emissions of lactating Danish Holstein cows using Fourier transform mid-infrared spectroscopy of milk. J. Dairy Sci. https://doi.org/10.3168/jds.2017-13014.

Shetty, N., P. Løvendahl, M. S. Lund, and A. J. Buitenhuis. 2017b. Prediction and validation of residual feed intake and dry matter intake in Danish lactating dairy cows using mid-infrared spectroscopy of milk. J. Dairy Sci. 100:253-264. https://doi.org/10.3168/ jds.2016-11609.

Soyeurt, H., C. Bastin, F. G. Colinet, V. M.-R. Arnould, D. P. Berry, E. Wall, F. Dehareng, H. N. Nguyen, P. Dardenne, J. Schefers, J. Vandenplas, K. Weigel, M. Coffey, L. Théron, J. Detilleux, E. Reding, N. Gengler, and S. McParland. 2012. Mid-infrared prediction of lactoferrin content in bovine milk: Potential indicator of mastitis. Animal 6:1830-1838. https://doi.org/10.1017/ S1751731112000791.

Soyeurt, H., I. Misztal, and N. Gengler. 2010. Genetic variability of milk components based on mid-infrared spectral data. J. Dairy Sci. 93:1722-1728. https://doi.org/10.3168/jds.2009-2614.

Toledo-Alvarado, H., A. I. Vazquez, G. de los Campos, R. J. Tempelman, G. Bittante, and A. Cecchinato. 2018. Diagnosing pregnancy status using infrared spectra and milk composition in dairy cows. J. Dairy Sci. 101:2496-2505. https://doi.org/10.3168/jds.2017 $-13647$.

Vazquez, A. I., D. M. Bates, G. J. M. Rosa, D. Gianola, and K. A. Weigel. 2010. Technical note: an R package for fitting generalized linear mixed models in animal breeding. J. Anim. Sci. 88:497-504. https://doi.org/10.2527/jas.2009-1952.

Wang, Q., and H. Bovenhuis. 2018. Genome-wide association study for milk infrared wavenumbers. J. Dairy Sci. 101:2260-2272. https:// doi.org/10.3168/jds.2017-13457.

Wang, Q., A. Hulzebosch, and H. Bovenhuis. 2016. Genetic and environmental variation in bovine milk infrared spectra. J. Dairy Sci. 99:6793-6803. https://doi.org/10.3168/jds.2015-10488. 